\title{
During COVID-19, which is more effective in work accident prevention behavior of healthcare professionals: Safety awareness or fatalism perception?
}

\author{
Özgün Ünal \\ DR, Department of Healthcare Management, Business Faculty, Sakarya University, Sakarya, Turkey
}

Received 25 August 2020

Accepted 12 September 2020

\begin{abstract}
.
BACKGROUND: As the pandemic process, COVID-19 has a serious occupational safety risk for healthcare professionals. Therefore, determining their health and safety perceptions and attitudes in the pandemic process is very important. This study aims to determine which is more effective in work accident prevention behavior: safety awareness and competencies of healthcare professionals or perception of fatalism.

METHOD: For this purpose, a questionnaire was applied to 326 healthcare professionals. The questionnaire consists of four parts: (1) demographic information of the employees, (2) scale of preventing occupational accidents, (3) fatalism perception scale in occupational health and safety, and (4) security awareness and competency scale. Descriptive statistical methods, multiple regression and correlation analysis were used in the analysis of the data.

RESULTS: It was determined that the participants' safety awareness and competencies were at the high level and their fatalism perceptions were at the low level. The average of the responses given by the participants to the scale of preventing work accidents was above the middle level. According to the study, the safety awareness and competencies of health workers were found to be about three times more effective on the behavior of preventing work accidents than the perception of fatalism. CONCLUSION: In conclusion, it is important to recommend managers to take the step to increase the safety awareness and competencies of those working in their institutions.
\end{abstract}

Keywords: COVID-19, fatalism perception, occupational safety and health, safety awareness and competencies, work accident prevention behavior

\section{Introduction}

The new coronavirus disease first appeared in Wuhan/China in December 2019 and has subsequently spread rapidly all over the world. This new virus, globally known as COVID-19, has affected all humanity and caused radical changes in daily life, and

*Address for correspondence: Özgün Ünal, Business School, Sakarya University, 54187 Esentepe Campus, Serdivan, Sakarya, Turkey. Tel.: +90 26429562 56; E-mail: ozgununal@ sakarya.edu. tr. ORCID: orcid.org/0000-0002-1245-2456. has been declared a pandemic disease by the World Health Organization [1]. It is thought that coronavirus is transmitted by spreading droplets into the environment by sneezing and coughing through infected individuals, and inhalation of these droplets by healthy individuals [2]. A recent study assumed that contamination of the coronavirus to healthcare workers is often transmitted in polyclinics, emergency departments, intensive care units, services, imaging rooms and ambulances [3]. In these work environments, hea1th workers are at high risk of becoming infected, because of the close contact with infected individuals. 
Additionally, there is an extraordinary intensity in hospitals due to the coronavirus disease, thereby increasing the workload of healthcare professionals. The extraordinary workload of employees also increases the likelihood of unexpected negative consequences arising from their work [4].

According to the Occupational Health and Safety Law in Turkey [5], occupational accidents are defined as "an event occurring in the workplace or due to the conduct of the work, causing death or making body integrity mentally or physically disabled." In this context, health professionals infected with coronavirus during healthcare to coronavirus patients should be considered as a work accident. The Turkish Medical Association supports this view (TMA) [6], defining an occupational accident as "the damage caused to a person in the workplace or from a sudden event caused by work." For this reason, TMA states that healthcare professionals who get COVID-19 infection at any time in their work should be considered as an occupational accident. According to this information, it will not be wrong to consider coronavirus as an important occupational health and safety threat for healthcare professionals.

Occupational health and safety issues seem to be a matter of considerable importance in Turkey as well as all over the world. However, occupational health and safety are dealt with in a more technical manner in Turkey [7] and the place of the human factor in the occupational health and safety is ignored [8]. All work accidents can be eliminated by training, awareness, proactive approaches and appropriate methods [8,9]. Gan et al. [10] state that environmental factors, organizational factors, technology and equipment used in the working system enable healthcare workers to do their work safely. For that, it is very important to determine the awareness and attitudes of healthcare professionals as related to occupational health and safety.

The fundamental purpose of occupational health and safety applications in the health sector is to create a safe working environment without physical, chemical, biological, ergonomic hazards and risks, occupational diseases and occupational accidents occurring in the working environment [11]. The mentioned definition also points to the responsibilities of management regarding occupational health and safety. On the other hand, due to occupational health and safety associated with employee behavior, employees also have the responsibility $[12,13]$. Especially in service companies, failure to comply with the occupational health and safety rules will bring work accidents [9]. A previous study reveals that the commitment of management to occupational health and safety practices does not affect occupational health and safety performance exclusively, but it can be improved by ensuring employee participation [8]. According to the study, it is implied that occupational health and safety is not a one-sided process, it is possible by ensuring the participation of all employees. Whereas, two types of employee behavior may arise in organizations for occupational health and safety applications. The first type is the safe behavior of individuals with high awareness and high attention to occupational health and safety rules. The second type is to approach occupational health and safety practices from a fatalistic point of view and to ignore occupational health and safety applications, considering or believing that occupational accidents are inevitable and destiny [32]. At this point, two concepts occur; (1) security awareness and competence, and (2) the perception of fatalism.

Safety awareness and competence mean that employees are aware of their responsibilities regarding occupational health and safety while performing their occupations, also know the occupational health and safety rules and can deal with current occupational health and safety issues. Security awareness and competence are a very important factor for the security situation in organizations, are also directly related to the compliance of employees with security preventions [14]. Thus, safe behaviors of employees can be ensured by increasing their awareness of safety [15].

Fatalism is a philosophy based on the fact that everything is inevitable and people have no control over these events [16]. In the literature, studies on the fatalism indicate that individuals with high fatalism perception are more prone to take risks and do not take safety precautions $[17,18]$. According to the fatalistic approach, employees believe that work accidents are uncontrollable, and it is not possible to prevent them. In this respect, it is highly probable that employees with this idea will neglect their occupational health and safety applications and may encounter a work accident.

In the literature, there are studies examining the concepts of work accident prevention behaviors [33-35], security awareness and competency [8-17], and fatalism perception [36, 37]. On the other hand, there is no study in which variables are examined and compared together. In this study, handling the variables together and investigating whether security awareness and competency or fatalism perception are 
more effective in work accident prevention behaviors constitute the original value of this study.

Considering the coronavirus pandemic experienced today, it is very important for healthcare professionals not to be caught in coronavirus with safe behaviors, while they are performing their profession, as a work accident. It is very likely that coronavirus, which has the high risk of contamination, may be transmitted to the healthcare professional through a sudden carelessness and lead to serious harm. During the COVID-19 pandemic process, occupational health and safety practices are more important than ever before. This study aimed to determine whether the safety awareness and competencies or the perception of fatalism are more effective in the healthcare workers' occupational health and safety applications. The research question created to test this purpose:

In the COVID-19 pandemic, does health workers' awareness of safety and competence or perception of fatalism affect their work accident prevention behaviors more?

\section{Method}

\subsection{Participants}

The sampling of the study consists of Yenikent State Hospital employees which is connected to the provincial health directorate of Sakarya province in Turkey. A total of 660 employees (doctors, nurses, other healthcare professionals) are present in the hospital. According to Coşkun et al. [19], the sample size that will represent the universe of 660 is 242 . In the study it was aimed to reach at least 242 employees and a total of 326 participants were surveyed. The survey was collected using the online survey technique and carried out between 1/05/2020-10/05/2020.

\subsection{Measurements}

For the study, a questionnaire form consisting of four parts was used as a data collection tool, as shown;

Demographic Information: ages of employees', gender, marriage status, educational status, working time at the workplace, whether they have ever experienced a work accident in their professional lives, also whether they have experienced a work accident at their current workplace and experiences of the incident before the accident.

Security Awareness and Competence: A scale developed by Lin et al. [14], consists of five questions and evaluates the employees' security awareness and the ability to deal with security problems. The scale consists of phrases such as: "handling with security problems in the workplace" and "safety is the most important thing at work" and is created according to Likert style as 1- "I totally disagree" and 5- "I totally agree".

The Perception of Fatalism: The scale used was developed by Rundmo and Hale [20] and taken from the Havold and Nesset [21] study of which a Turkish translation was made by Dursun [7]. The scale consists of phrases such as "accidents happen suddenly and there is little you can do to prevent them" and "what will happen to you at the work is largely a matter of luck". The effectiveness and reliability analyses of the scale were made by Ünal et al. [8]. The scale consists of six questions and evaluates the fatalistic beliefs of employees regarding work accidents. The scale is created according to Likert style as 1- "I totally disagree" and 5- "I totally agree".

Work Accidents Behavior Prevention: The scales performed by Tuygun Toklu [22], Christopher et al. [23] and Glendon et al. [24] were adapted from the security condition survey. While the scales were originally developed for use in manufacturing enterprises, the adaptation of the scale to the health sector was made in this study. The scale consists of five phrases such as "Those who work at risky places use glasses, boots, gloves, masks, overalls, shoes, etc." and "Only those who are specifically assigned or necessary equipment can enter the risky places in my hospital". The scale is designed according to Likert style as 1- "I totally disagree" and 5- "I totally agree".

\subsection{Controlling the common method bias}

Social bias is an important problem in social sciences. For this reason, the following steps have been followed to take into account the recommendations of Podsakoff et al. (2003) in order to prevent possible social bias.

\subsubsection{The design of the study's procedures}

Protecting respondent anonymity and reducing evaluation apprehension: No information was requested from the participants to identify themselves in order to eliminate the possible problem that this situation may cause, and the participants were undertaken not to share their answers with third parties.

Improving scale items: In the scales used, there was no word that would not be known to the participants, the questions were clear and understandable. 


\subsubsection{Statistical controls}

Harman's singlefactor test: Within the scope of this frequently used model, all items were loaded on a single factor and factor analysis was performed. As a result of the analysis, the total variance announced was $26.16 \%$. It can be stated that the threat of social bias does not pose a threat to this study since this value is quite far from $50 \%$.

\subsection{Legal approvals}

Before the questionnaire, Sakarya University Ethics confirmed that it complied with the ethical principles administered by the Committee (Document No. E.4579) and necessary permits for the study were taken from the Sakarya Provincial Health Directorate and Turkey Ministry of Health.

\subsection{Analysis}

Obtained data were analyzed by SPSS version 22.0 statistical program. Descriptive statistical methods, validity and reliability analysis and multiple regression analysis were used for the analysis of the data.

\section{Results}

In the study, the reliability analyses of the scales used were made first. The Cronbach's alpha values of the scales used in the study were found to be 0.843 for "Fatalism Scale", 0.849 for "Work Accident Prevention Scale" and 0.831 for "Safety Awareness and Competency Scale". The originals of these scales were previously determined as 0.761 for "Fatalism Scale", 0.910 for "Work Accident Prevention Scale" and 0.835 for "Safety Awareness and Competency Scale" $[14,20]$. According to these findings, it has been observed that the scales have the necessary conditions for reliability [25].

In the study, exploratory factor analysis was applied to test the validity of the scales. In the test results of the scale, the Kaiser-Meyer-Olkin (KMO) sample adequacy was found to be as 0.863 . According to this result, it can be said that the sample size of the study is seen as sufficient [26]. The Bartlett sphericity test result was significant to evaluate the suitability of the data set for factor analysis $(p=0.000)$. The obtained result from the study showed that the data set was suitable for factor analysis [19].

As shown in Table 1, the scale was divided into three dimensions as a result of the factor analysis
Table 1

Exploratory factor analysis and reliability results of scales

\begin{tabular}{|c|c|c|c|}
\hline $\begin{array}{l}\text { Kaiser-Meyer-Olkin measure } \\
\text { of sampling adequacy }\end{array}$ & 0.863 & & \\
\hline \multicolumn{4}{|l|}{ Bartlett's test of sphericity } \\
\hline Approx. chi-square & 2311.740 & & \\
\hline df & 120.000 & & \\
\hline Sig. & 0.000 & & \\
\hline Total of variance & 59.850 & & \\
\hline Factors & Factor 1 & Factor 2 & Factor 3 \\
\hline Cronbach's alpha & 0.843 & 0.849 & 0.831 \\
\hline Eigenvalues & 4.211 & 3.246 & 1.019 \\
\hline$\%$ of variance & 21.439 & 20.424 & 17.987 \\
\hline Fatalism 3 & 0.846 & & \\
\hline Fatalism 4 & 0.836 & & \\
\hline Fatalism 2 & 0.810 & & \\
\hline Fatalism 1 & 0.688 & & \\
\hline Fatalism 6 & 0.656 & & \\
\hline Fatalism 5 & 0.639 & & \\
\hline Preventing work accidents 3 & & 0.799 & \\
\hline Preventing work accidents 4 & & 0.798 & \\
\hline Preventing work accidents 2 & & 0.786 & \\
\hline Preventing work accidents 5 & & 0.713 & \\
\hline Preventing work accidents 1 & & 0.686 & \\
\hline $\begin{array}{l}\text { Safety awareness } \\
\text { and competence } 4\end{array}$ & & & 0.778 \\
\hline $\begin{array}{l}\text { Safety awareness } \\
\text { and competence } 1\end{array}$ & & & 0.771 \\
\hline $\begin{array}{l}\text { Safety awareness } \\
\quad \text { and competence } 2\end{array}$ & & & 0.726 \\
\hline $\begin{array}{l}\text { Safety awareness } \\
\text { and competence } 3\end{array}$ & & & 0.674 \\
\hline $\begin{array}{l}\text { Safety awareness } \\
\text { and competence } 5\end{array}$ & & & 0.568 \\
\hline
\end{tabular}

of the scales used in the presented study. The total variance was $59.85 \%$. The perception of fatalism means $21,44 \%$ of the total variance, accident prevention means $20.42 \%$ of the total variance and security awareness and competency dimension means as $17.99 \%$ of the total variance.

The results of the confirmatory factor analysis of the scales are shown in Fig. 1. Also, the confirmatory factor analysis of the scales and comparisons of the compliance criteria are presented in Table 2 and standardized regression weight are presented in Table 3 As shown in Table 2, the criteria of all three scales are generally acceptable [26]. These results show that these scales may be usable.

The majority of the participants of the study are women with $62.9 \%$. The mean age of the participants is $36.44 \pm 8.67$ and the mean of their professional experience is $13.03 \pm 8.36$. Considering the education level, the participants are determined as $22.4 \%$ high school, $22.7 \%$ vocational school, $41.7 \%$ undergraduate and $13.5 \%$ graduate. Of the total, $66 \%$ of the participants have children. The majority of the participants are nurses $(57.1 \%)$, the rest of them are 


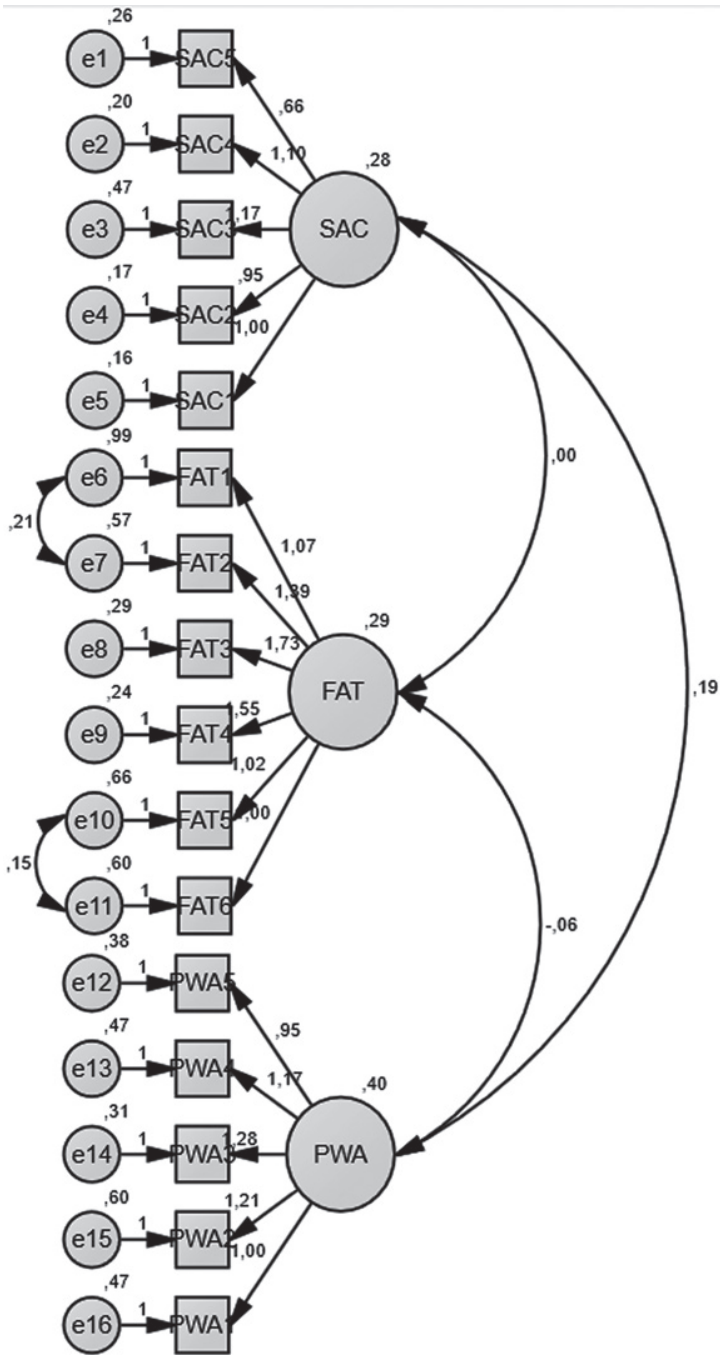

Fig. 1. Confirmatory factor analysis results.

Table 2

Acceptance ranges of the goodness of fit indices and findings from scales

\begin{tabular}{lccc}
\hline Criterion & Good fit & Perfect fit & Used scale \\
\hline Ki-square & & & 203.139 \\
$\quad($ CMIN $)$ & & & \\
DF & & & 99 \\
CMIN/DF & $X^{2} / \mathrm{DF} \leq 3$ & 2.052 \\
NFI & $0.90 \leq \mathrm{NFI}<0.95$ & $0.95 \leq \mathrm{NFI}$ & 0.914 \\
TLI $(\mathrm{NNFI})$ & $0.90 \leq \mathrm{NNFI}<0.95$ & $0.95 \leq \mathrm{NNFI}$ & 0.944 \\
IFI & & $0.95 \leq \mathrm{IFI}$ & 0.954 \\
CFI & $0.90 \leq \mathrm{CFI}<0.95$ & $0.95 \leq \mathrm{CFI}$ & 0.953 \\
RMSEA & $0.05<\mathrm{RMSEA}<0.08$ & $\mathrm{RMSEA} \leq 0.05$ & 0.057 \\
GFI & $0.85 \leq \mathrm{GFI}<0.90$ & $0.90 \leq \mathrm{GFI}$ & 0.928 \\
RMR & $0.05 \leq \mathrm{RMR} \leq 0.08$ & $\mathrm{RMR}<0.05$ & 0.050 \\
\hline
\end{tabular}

Source: Karagöz [26].
Table 3

Standardized regression weights

\begin{tabular}{lccc}
\hline & Items & & Estimate \\
\hline SAC1 & $<-$ & SAC & 0.802 \\
SAC2 & $<-$ & SAC & 0.774 \\
SAC3 & $<-$ & SAC & 0.673 \\
SAC4 & $<-$ & SAC & 0.791 \\
SAC5 & $<-$ & SAC & 0.562 \\
PWA1 & $<-$ & PWA & 0.682 \\
PWA2 & $<-$ & PWA & 0.703 \\
PWA3 & $<-$ & PWA & 0.826 \\
PWA4 & $<-$ & PWA & 0.736 \\
PWA5 & $<-$ & PWA & 0.703 \\
FAT6 & $<-$ & FAT & 0.571 \\
FAT5 & $<-$ & FAT & 0.561 \\
FAT4 & $<-$ & FAT & 0.86 \\
FAT3 & $<-$ & FAT & 0.867 \\
FAT2 & $<-$ & FAT & 0.703 \\
FAT1 & $<-$ & FAT & 0.499 \\
\hline
\end{tabular}

Table 4

Means of responses to scales

\begin{tabular}{lcc}
\hline & Mean & Std. deviation \\
\hline Security awareness and competence & 4.252 & 0.562 \\
The perception of fatalism & 3.464 & 0.773 \\
Work accidents prevention behavior & 3.705 & 0.776 \\
\hline
\end{tabular}

Table 5

Correlation analysis findings

\begin{tabular}{lcc}
\hline & 1 & 2 \\
\hline Security awareness and competence $^{1}$ & 1 & \\
The perception of fatalism $^{2}$ & -0.019 & 1 \\
Work accidents prevention behavior $^{3}$ & $0.520^{* *}$ & $-0.147^{* *}$ \\
\hline
\end{tabular}

doctors $(10.1 \%)$ and other health workers $(32.8 \%)$. Besides, especially for the healthcare workers $21.2 \%$ of the participants were exposed to the coronavirus.

The means of the responses given by the participants in the study are given in Table 4. As shown, participants' safety awareness and competencies are at the high level and their perception of fatalism is at the low level. Besides, the mean of the answers given by the participants to the scale of preventing work accidents was above the middle level.

Correlation analysis findings examining the relationship between research variables are presented in Table 5. Although there is no statistically significant difference between security awareness and competence and fatalism perception among research variables, there is an opposed relation. Also, there is a positive relation between security awareness and competence and the behavior of preventing occupational accidents and a negative relation between the perception of fatalism and the behavior of preventing occupational accidents. 


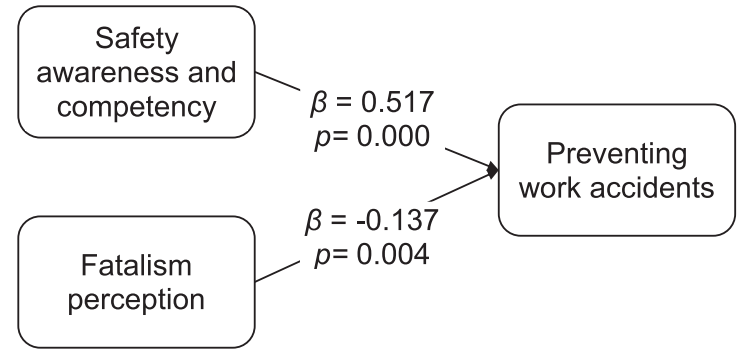

Fig. 2. The effect of security awareness and competence and fatalism perception on the prevention of work accidents.

In Fig. 2, the results of the regression analysis, in which the research purpose is tested, are presented. As shown, safety awareness and competence affect the behavior of preventing work accidents positively ( $\beta=0.517 ; p=0.000)$, and the fatalism perception affects negatively $(\beta=-0.137 ; p=0.004)$. Considering the security awareness and competence and the effects of fatalism perception on work accident prevention behavior, It is determined that security awareness and competence have the higher effect on work accident prevention behavior. As a result of the Friedman test conducted to examine the significance test of the difference between the two averages, it was concluded that the difference between safety awareness and competence and fatalism perception was statistically significant, since the $\mathrm{p}$ value was found to be less than $0.005(p=0.000)$.

\section{Discussion and conclusion}

The present study aimed to determine which is more effective in work accident prevention behavior during the COVID-19 pandemic process, 'safety awareness and competencies of healthcare professionals' or 'perception of fatalism'. According to the study, safety awareness and competency levels of healthcare workers are at the high level. These results are supported by the studies in the literature [7, 27-29]. According to this finding, healthcare professionals know the safety rules related to their responsibilities, understand the present risks, also are aware of handling these risks and comply with the safety rules. Employees' awareness of security and competence levels seem to be very important with dealing COVID-19 virus, which is at high risk of contamination. According to another finding of the study, the worker's accident prevention behavior was found close to the high level. Findings of the study, which are similar to studies in the literature [22], are evaluated with the result of the high level of safety awareness and competence of the employees, so it can be said that the healthcare professionals are very conscious about the occupational health and safety in the pandemic process. Another finding of the study, which is compatible with these results, shows that health workers do not leave the issue of occupational health and safety to chance, due to the result that their perception of fatalism is at the low level. Similar with our study, Rundmo and Hale [20] found that participants' safety awareness was at the high level and their fatalism perceptions were at the low level.

Another finding obtained from the present study shows that increases in the health workers' safety awareness and competencies may elevate the behavior to prevent work accidents. Besides, when the fatalism perceptions are increased, it seems that the behaviors of preventing work accidents are declined. These results are supported by many studies in the literature. In their research, Wang et al. [29] and Karanikas et al. [30] found that safety awareness affects safe behavior and, similarly, Choi et al. [15] proposed that the safe behavior of employees can be achieved by increasing their awareness of safety. According to Loney et al. [31], failure to comply with health and safety procedures, as well as lack of awareness about risks associated with certain professional activities, increases work accidents. In another study, Rundmo and Hale [20] declared that fatalism perception negatively affects the attitudes of the participants regarding occupational health and safety. Kayani et al. [18] implied that increases in individuals' perception of fatalism may display more risky actions.

One of the important findings from the present study is the conclusion that the safety awareness and competencies of the employees have the higher impact on the health workers' behavior of preventing occupational accidents compared to their fatalism perceptions. Health workers' safety awareness and competencies were found to be about three times more effective on the behavior of preventing work accidents than the perception of fatalism. According to the Turkey Health Ministry, it is declared that 7428 health workers have been contaminated with coronavirus as of April 29, 2020. At this date, the total number of cases were as 117,589 , and the rate of infected health workers was $6.31 \%$. The healthcare workers in Turkey have a very low infection rate. Meanwhile, the situation supports the conclusion that the safety awareness and competencies of the health workers obtained from the presented study have the higher impact on the work accident prevention behavior than the perception of fatalism. 
The results of the study show that health workers are generally conscious of occupational health and safety and take into consideration the occupational health and safety rules while doing their work.

\section{Implication for occupational health and safety}

The present study was carried out to determine the perceptions and attitudes of Turkish healthcare professionals about occupational health and safety during the COVID-19 pandemic process and to propose some practical suggestions. The most important of these suggestions reveals that occupational health and safety is not a factor of chance and that work accidents can be eliminated if necessary measures are taken, and it is necessary to support employees with training, conferences, informative notes and examples. The findings of the study may provide some evidence that occupational health and safety will be successful with scientific methods and employee participation. As a conclusion, it is considered important and recommends managers to take steps to increase occupational health and safety practices, especially safety awareness and competence of employees.

\section{Limitation}

The main limitation of the study is the limited research which was conducted in a single public hospital. So, it cannot be generalized with all healthcare professionals. Another limitation is data collection performed with online survey technique due to the pandemic. When using the survey technique, it is important to explain the issues that the participants do not understand from the survey technique. The online survey method partially lacks this advantage. This situation constitutes another limitation of the study.

\section{Acknowledgments}

The author is grateful to Sema Ünal, Mehmet Karakaya and Bilge Güneş Karakaya who contributed to the survey process of the study.

\section{Conflict of interest}

The author declares no potential conflicts of interest with respect to the research, authorship, and/or publication of this article.

\section{Funding}

The author received no financial support for the research, authorship, and/or publication of this article.

\section{References}

[1] World Health Organization. WHO Director-General's opening remarks at the media briefing on COVID-19 2020 [cited 2020 May 08]. Available from: https://www. who.int/dg/speeches/detail/who-director-general-s-openi ng-remarks-at-the-media-briefing-on-COVID-19-11march-2020

[2] Carver PE, Phillips J. Novel Coronavirus (COVID-19): What You Need to Know. Workplace Health Saf. 2020; 68(5):250.

[3] Kang SK. COVID-19 and MERS Infections in Healthcare Workers in Korea, Saf Health Work, 2020. [cited 2020 May 13]. Available from: https://doi.org/10. 1016/j.shaw.2020.04.007

[4] Öztürk YE, Türktemiz H, Akdağ T. Dozimetre taşıyan sağlık çalışanlarında iş yükünün iyonlaştırıcıradyasyon risk algisina etkisi. Hacettepe Health Admin J. 2017;20(2):20318.

[5] Presidency of the Republic of Turkey. Occupational Health and Safety Law. 2012 [Cited 2020 May 6]. Available from: https://www.mevzuat.gov.tr/MevzuatMetin/1.5.6331.pdf

[6] Turkish Medical Assocation. Sağlık çalışanında COVID-19 tanısı iş kazası veya meslek hastalığıdır. 2020 [Cited 2020 May 6]. Available from: https://www.ttb.org.tr/haber_gost er.php?Guid=92238894-726a-11ea-b12d-d839943d748d

[7] Dursun S. An application for the impact on the safety performance of safety culture. Uludag University, Master of Science, Unpublished Master Thesis, Turkey, 2011.

[8] Ünal Ö, Akbolat M, Amarat M, Tilkilioğlu S. The Role of the Human Factor in Occupational Safety and Health Performance. International Int J Occup Saf Ergon, 2018:(Online First Article): 1-17. doi:10.1080/10803548.2018.1554932

[9] Demir B, Demir N. Occupational Health and Safety Act of 6631 Announcement of the Public Sector Implementation and Current Liabilities. J of Ist Aydin Uni. 2016:29:167-94.

[10] Gan WH, Lim JW, David KOH. Preventing intra-hospital infection and transmission of COVID-19 in healthcare workers. Saf Health Work. 2020(Online First Article) https: //doi.org/10.1016/j.shaw.2020.03.001

[11] Özkan Ö, Emiroğlu ON. Hastane Sağlık çalışanlarına Yönelik İşçi Sağlığı ve İş Güvenliği Hizmetleri. C.U. J. of Nurs. High School. 2006;10(3):43-51.

[12] Feng Y, Teo EA L, Ling FYY, Low SP. Exploring the interactive effects of safety investments, safety culture and project hazard on safety performance: An empirical analysis. Int J Constr Proj Manag. 2014;32(6):932-43.

[13] Leung MY, Liang Q, Olomolaiye P. Impact of job stressors and stress on the safety behavior and accidents of construction workers. J Manage Eng. 2016;32(1):04015019.

[14] Lin S-H, Tang W-J, Miao J-Y, Wang Z-M, Wang P-X. Safety climate measurement at the workplace in China: A validity and reliability assessment. Saf Sci. 2008;46(7):1037-46.

[15] Choi B, Ahn S, Lee S. Role of social norms and social identifications in the safety behavior of construction workers. I: Theoretical model of safety behavior under social influence. J Constr Eng M. 2017;143(5):04016124. 
[16] Turkish Language Association. Kadercilik (Yazgıcılık). 2018 [Cited 2020 May 8]. Available from: http://www. tdk.gov.tr/index.php?option=com_bts\&arama=kelime \&gui $\mathrm{d}=$ TDK.GTS.5a4ec34c3e07d1.87202623

[17] Aytac S, Dursun S. The Effect on the Safety Culture of Occupational Accidents and Safety Behavior: The Case of Turkey. In Proceedings of International Academic Conferences (No. 7809355). International Institute of Social and Economic Sciences. 2018

[18] Kayani A, King MJ, Fleiter J. Fatalism and Road Safety in Developing Countries, With A Focus on Pakistan. J Australas Coll Road Saf. 2011;22(2):41-7.

[19] Coşkun R, Altunışık R, Bayraktaroğlu S, Yıldırım E. Sosyal bilimlerde araştırma yöntemleri. 8. Press. Sakarya: Sakarya Bookstore; 2015;137.

[20] Rundmo T, Hale AR. Managers' attitudes towards safety and accident prevention. Saf Sci. 2003;41(7):557-74.

[21] Havold JI, Nesset E. From safety culture to safety orientation: validation and simplification of a safety orientation scale using a sample of seafarers working for Norwegian ship owners. Saf Sci. 2009;47(3):305-26.

[22] Tuygun Toklu, A. çalışanlarda İş Sağlığı ve Güvenliği Uygulamalarının Örgütsel Bağlılık, İşe Yabancılaşma Ve İş Performansina Olan Etkisinin İncelenmesi. Gebze Technical University, UnpublishedPhD Thesis, Turkey, 2016.

[23] Christopher CO, Paul OO, Badejo AE. Promoting ethical human resource management practices in work organizations in Nigeria: Roles of HR professionals. J Hum Resour. 2012;2(2):116-32.

[24] Glendon AI, Litherland DK. Safety climate factors, group differences and safety behaviour in road construction. Saf Sci. 2001;39:157-88.

[25] Kalayci S. Application of SPSS; Very Variable Statistical Techniques, 6. Press, Ankara: Asil Publishing; 2014.

[26] Karagoz Y. SPSS 21.1 Biostatistics Application. Ankara: Nobel Publishing; 2014.

[27] Akdeniz B, Giderler C, Özler, NDE. Can other disciplines support occupational health and safety efforts? Importance of safety culture: A study on a coal mine Institution. Acta acad Karvin. 2018;18(4):5-16.
[28] Ma Q, Yuan J. Exploratory study on safety climate in Chinese manufacturing enterprises. Saf Sci. 2009; 47(7):1043-46.

[29] Wang M, Sun J, Du H, Wang C. Relations between Safety Climate, Awareness, and Behavior in the Chinese Construction Industry: A Hierarchical Linear Investigation. Advances in Civil Engineering, [Internet]. 2018 [cited 2020 May 19]. Available from: https://www.hindawi. com/journals/ace/2018/6580375/

[30] Karanikas N, Melis DJ, Kourousis KI. The balance between safety and productivity and its relationship with human factors and safety awareness and communication in aircraft manufacturing. Saf Health Work. 2018;9(3):257-64.

[31] Loney T, Cooling RF, Aw TC. Lost in translation? Challenges and opportunities for raising health and safety awareness among a multinational workforce in the United Arab Emirates. Saf Health Work. 2012;3(4):298-304.

[32] Topçuoğlu H, Özdemir ş. İs Sağlığıve Güvenliğinde Davranış Değişikliği Yaratma Süreci. Occupational Health and Safety Congress, 2003: Publication no E/2003/317, Adana/Turkey, 2-3.

[33] Zwetsloot G, Leka S, Kines P. Vision zero: from accident prevention to the promotion of health, safety and well-being at work. Policy Pract. Health Saf. 2017;15(2):88-100.

[34] Thepaksorn P, Thongjerm S, Incharoen S, Siriwong W, Harada K, \& Koizumi A. Job safety analysis and hazard identification for work accident prevention in para rubber wood sawmills in southern Thailand. J Occup Health. 2017;16-0204.

[35] Long S, Smith BK, Ng EH, Sun C. Work zone safety: physical and behavioral barriers in accident prevention (No. cmr 14-013). Missouri. Dept. of Transportation. Division of Construction and Materials. 2014.

[36] Patwary MA, O'Hare WT, Sarker MH. Occupational accident: An example of fatalistic beliefs among medical waste workers in Bangladesh. Saf Sci. 2012;50(1):76-82.

[37] Dursun S. An aplication for the impact on safety performance of safety culture. Uludag University, SBE, Master of Science, Unpublished PhD Thesis, 2011. 